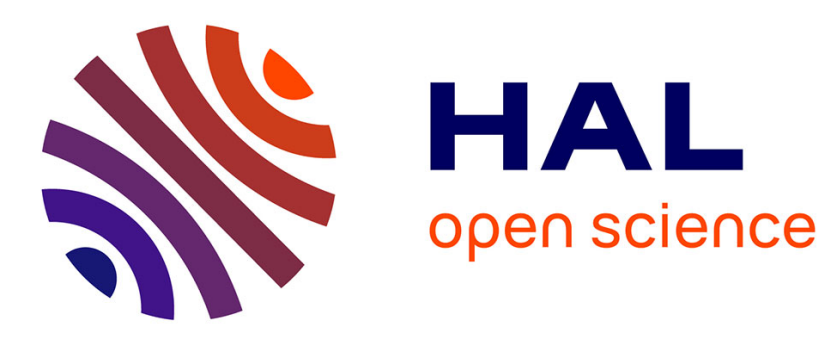

\title{
Hypo- and hyperkalaemia in heart failure. Navigating between Scylla and Charybdis
}

Patrick Rossignol, Faiez Zannad

\section{To cite this version:}

Patrick Rossignol, Faiez Zannad. Hypo- and hyperkalaemia in heart failure. Navigating between Scylla and Charybdis. European Journal of Heart Failure, In press, 22 (8), pp.1399-1401. 10.1002/ejhf.1791 . hal-02978555

\section{HAL Id: hal-02978555 \\ https://hal.univ-lorraine.fr/hal-02978555}

Submitted on 3 Dec 2020

HAL is a multi-disciplinary open access archive for the deposit and dissemination of scientific research documents, whether they are published or not. The documents may come from teaching and research institutions in France or abroad, or from public or private research centers.
L'archive ouverte pluridisciplinaire HAL, est destinée au dépôt et à la diffusion de documents scientifiques de niveau recherche, publiés ou non, émanant des établissements d'enseignement et de recherche français ou étrangers, des laboratoires publics ou privés. 
Hypo- and hyperkalaemia in heart failure. Navigating between Scylla and Charybdis.

Patrick Rossignol $^{1}$, Faiez Zannad ${ }^{1}$

${ }^{1}$ Université de Lorraine, Centre d'Investigation Clinique Plurithématique 1433 -INSERMCHRU de Nancy, Inserm U1116 \& FCRIN INI-CRCT (Cardiovascular and Renal Clinical Trialists), Vandoeuvre-les-Nancy, France

\section{Corresponding author}

Professor Patrick Rossignol

Centre d'Investigations Cliniques-INSERM CHRU de Nancy,

Institut Lorrain du Cœur et des Vaisseaux Louis Mathieu,

4 Rue du Morvan, 54500 Vandoeuvre lès Nancy, France.

E-mail: p.rossignol@chru-nancy.fr 
In chronic kidney and cardiovascular disease clinical trials and registries, both hypokalaemia and hyperkalaemia have consistently been found to be associated with poor clinical outcomes (1) . In this Journal issue, Cooper et al., using the nationwide Swedish Heart Failure registry, report a $\mathrm{V}$-shape relationship between potassium and death in a chronic heart failure population with reduced ejection fraction, with a narrow Nadir of "Normal" serum potassium concentration of $4.2 \mathrm{mmol} / \mathrm{l}$ associated with the lowest death rate(2). A similarly narrow (4.2$4.5 \mathrm{mmol} / \mathrm{l})$ Nadir was observed in a similarly large Danish nationwide registry(3). In their important report, Copper et al(2) used extensive multivariable adjustment, attempting to mitigate the many expected confounders, which has commonly confounded multiple previous similar reports. They have also carefully looked at both sides of the coin, i.e. hypokalaemia and to hyperkalaemia and their respective associations with both short-term and long-term outcomes. A major finding was that hypokalaemia was both a risk marker and a risk factor associated with short- and long-term mortality, while hyperkalaemia was a risk factor associated with mortality, only short-term, and a risk marker over time (2). The risk associated with hyperkalaemia in heart failure is mainly a consequence of the frequent discontinuation and/or underdosing of renin angiotensin aldosterone system inhibitors (RAASi), caused by incident hyperkalaemia or the concern of thereof (4)

The report of Copper et al. rightly conclude that "clinicians should be targeting a narrower goal potassium range than what has traditionally been considered within the normal range"(2) (i.e. $4-5 \mathrm{mmol} / \mathrm{l}$ ). How can this be achieved is an important practical issue. Indeed, despite its strong rationale, how and whether the specific management of hypokalaemia and hyperkalaemia may ultimately lead to improved clinical outcomes still lacks randomised evidence. How best to prevent mortality related to hypokalaemia, and whether the use of potassium binders may ultimately improve outcomes whilst facilitating the uptitration of RAASi in heart failure patients prone to hyperkalaemia or their maintenance in hyperkalaemic 
patients warrant appropriate testing. The ongoing DIAMOND study, is a randomised trial examining the safety and efficacy (cardiovascular death or hospitalization as primary endpoint) of the potassium binder patiromer for the enablement of spironolactone and management of hyperkalaemia in subjects receiving renin angiotensin aldosterone system inhibitor (RAASi) medications for the treatment of heart failure, clinicaltrial.gov NCT03888066). Interestingly, Nunez et al, in a (Spanish) registry setting, reported that potassium normalisation in initially hypokalaemic or hyperkalaemic chronic heart failure patients ultimately experienced improved clinical outcomes(5).

A key element is to properly monitor potassium levels. Guidelines recommend close monitoring of serum potassium and renal function during periods of RAAS inhibitor titration until the patient is stable and at regular intervals thereafter (6). In the landmark MRA randomised trials such as RALES (Randomized Aldactone Evaluation Study), EPHESUS, and EMPHASIS- HF, management of RAAS inhibitor dosing was dynamic and algorithmically driven by a protocolised monitoring of serum potassium and creatinine (7).

In the EPHESUS (Eplerenone Post-Acute Myocardial Infarction Heart Failure Efficacy and Survival Study), and EMPHASIS-HF (Eplerenone in Mild Patients Hospitalization and Survival Study in Heart Failure) trials, the median [interquartile range (IQR)] follow-up was 16 (12-20) and $21(10-33)$ months, respectively. The anticipated number of serum $\mathrm{K}+$ measurements according to the protocol was 10 (8-11) and 7 (5-10) in each trial, respectively. The median (IQR) number of actual serum $\mathrm{K}+$ measurements was $11(9-13)$ and 8 (5-11), respectively, i.e. some additional measurements were performed after a clinical event or after a non-anticipated medication change. Using these databases, adding timeupdated variables including $\mathrm{K}+$ concentrations and mineralocorticoid receptor antagonists (MRA) intake improved the prediction of cardiovascular death (on top of the MAGGIC score) in patients with heart failure eligible for RAASi and MRA therapy, while 
hypokalaemia and hyperkalaemia actually carried the same level of risk (8). Importantly, more frequent $\mathrm{K}+$ measurements improved the association between risk score and outcome. $\mathrm{A}$ web-based calculator was created to allow easy determination of this new risk score (http://cic-p-nancy.fr/CardiovascularriskscoreCalculator/), from which it was hypothesised that this new risk score including MRA usage and $\mathrm{K}+$ may be of value in helping physicians to better use MRAs, avoid unnecessary and potentially detrimental permanent discontinuations, and therefore improve cardiovascular outcomes in patients with chronic HFrEF or HF after acute myocardial infarction with left ventricular dysfunction (8).

Unfortunately, close serum potassium monitoring is uncommon in real-life settings, with less than one-third of patients starting MRA therapy being monitored for the "minimum minimorum" (i.e. early post-initiation then within three months) in surveys performed in the US and in Sweden (9, 10). In the US survey, 5782 (55.4\%) and 2328 (22.3\%) patients received no testing in early or extended follow-up, respectively(9). Disease management programs may play a key role (11). Further empowering disease management programs with remote monitoring tools is highly desirable. Strikingly, in a recent prospective 5-day-a-week home monitoring survey in heart failure patients post-discharge combining haemoglobin/haematocrit, potassium and creatinine measurements using capillary blood measurements with the i-STAT analyser, home monitoring was able to capture a substantial number of clinically relevant cardio-renal (congestion/decongestion, worsening renal function) and electrolyte events (hypokalaemia/hyperkalaemia) which are frequently overlooked and potentially actionable (Figure) (12).

Recent attempts to non-invasively detect hyperkalaemia with 2-ECG leads have been developed (13). However, whether such devices are also able to detect hypokalaemia is unknown. Furthermore, whether such an approach would be sufficiently sensitive to detect subtle and potentially relevant potassium variations around the narrow Nadir of $4.2 \mathrm{mmol} / \mathrm{l}$, is 
questionable, owing to the well-known lack of sensitivity of the ECG. Such uncertainties along with the unmet clinical need of properly monitoring potassium in patients prone to experience dyskalaemia clearly opens new and interesting avenues for developing novel technologies.

\section{Acknowledgements}

PR and FZ are supported by the RHU Fight-HF, a public grant overseen by the French National Research Agency (ANR) as part of the second "Investissements d'Avenir" program (reference: ANR15-RHUS-0004), and by the French PIA project "Lorraine Université d'Excellence" (reference: ANR15-IDEX-04-LUE).

\section{Disclosures}

Dr. Rossignol reports grants and personal fees from AstraZeneca, Bayer, CVRx, personal fees from Fresenius, grants and personal fees from Novartis, personal fees from Grunenthal, Servier, Stealth Peptides, Vifor Fresenius Medical Care Renal Pharma, Idorsia, NovoNordisk, Ablative Solutions, G3P, Corvidia, Relypsa, outside of the submitted work; and is a cofounder of CardioRenal, a company developing a telemonitoring loop in heart failure (including potassium measurements).

Dr. Zannad reports personal fees from Janssen, personal fees from Bayer, personal fees from Boston Scientific, personal fees from Amgen, personal fees from CVRx, personal fees from Boehringer, other from cardiorenal, personal fees from AstraZeneca, personal fees from Vifor Fresenius, personal fees from Cardior, personal fees from Cereno pharmaceutical, personal fees from Applied Therapeutics, personal fees from Merck, other from CVCT, personal fees from Novartis, outside the submitted work; and is a cofounder of CardioRenal, a company developing a telemonitoring loop in heart failure (including potassium measurements). 
1. Kovesdy CP, Matsushita K, Sang Y, Brunskill NJ, Carrero JJ, Chodick G, et al. Serum potassium and adverse outcomes across the range of kidney function: a CKD Prognosis Consortium meta-analysis. Eur Heart J. 2018.

2. Cooper LB, Lina Benson L, Mentz RJ, Savarese G, DeVore AD, Carrero JJ, et al. Association between Potassium Level and Outcomes in Heart Failure wi 1 th Reduced Ejection Fraction: ACohort Study from the Swedish Heart Failure Registry. Eur J Heart Fail. 2020; In press.

3. Aldahl M, Jensen AC, Davidsen L, Eriksen MA, Moller Hansen S, Nielsen BJ, et al. Associations of serum potassium levels with mortality in chronic heart failure patients. Eur Heart J. 2017;38(38):2890-6.

4. Lund LH, Pitt B. Is hyperkalaemia in heart failure a risk factor or a risk marker? Implications for renin-angiotensin-aldosterone system inhibitor use. Eur J Heart Fail. 2018;20(5):931-2.

5. Nunez J, Bayes-Genis A, Zannad F, Rossignol P, Nunez E, Bodi V, et al. Long-Term Potassium Monitoring and Dynamics in Heart Failure and Risk of Mortality. Circulation. 2017;137(13):1320-30.

6. Ponikowski P, Voors AA, Anker SD, Bueno H, Cleland JG, Coats AJ, et al. 2016 ESC Guidelines for the diagnosis and treatment of acute and chronic heart failure: The Task Force for the diagnosis and treatment of acute and chronic heart failure of the European Society of Cardiology (ESC). Developed with the special contribution of the Heart Failure Association (HFA) of the ESC. Eur J Heart Fail. 2016;18(8):891-975.

7. Zannad F, Rossignol P. Cardiorenal Syndrome Revisited. Circulation. 2018;138(9):92944.

8. Rossignol P, Duarte K, Girerd N, Karoui M, McMurray JJV, Swedberg K, et al. Cardiovascular risk associated with serum potassium in the context of mineralocorticoid receptor antagonist use in patients with heart failure and left ventricular dysfunction. Eur J Heart Fail. 2020.

9. Cooper LB, Hammill BG, Peterson ED, Pitt B, Maciejewski ML, Curtis LH, et al. Consistency of Laboratory Monitoring During Initiation of Mineralocorticoid Receptor Antagonist Therapy in Patients With Heart Failure. JAMA. 2015;314(18):1973-5.

10. Nilsson E, De Deco P, Trevisan M, Bellocco R, Lindholm B, Lund LH, et al. A real-world cohort study on the quality of potassium and creatinine monitoring during initiation of mineralocorticoid receptor antagonists in patients with heart failure. Eur Heart J Qual Care Clin Outcomes. 2018;4(4):267-73.

11. Alla F, Agrinier N, Lavielle M, Rossignol P, Gonthier D, Boivin JM, et al. Impact of the interruption of a large heart failure regional disease management programme on hospital admission rates: a population-based study. Eur J Heart Fail. 2018;20(6):1066-8.

12. Rossignol P, Fay R, Girerd N, Zannad F. Daily home monitoring of potassium, creatinine and estimated plasma volume in heart failure post discharge ESC Heart Fail. 2020; In press. 
13. Galloway CD, Valys AV, Shreibati JB, Treiman DL, Petterson FL, Gundotra VP, et al. Development and Validation of a Deep-Learning Model to Screen for Hyperkalemia From the Electrocardiogram. JAMA Cardiol. 2019;4(5):428-36.

Figure: Individual home blood capillary monitoring in a heart failure patient post-discharge after a decompensation (Rossignol et al., ESC Heart Fail 2020 in press)

Kalemia

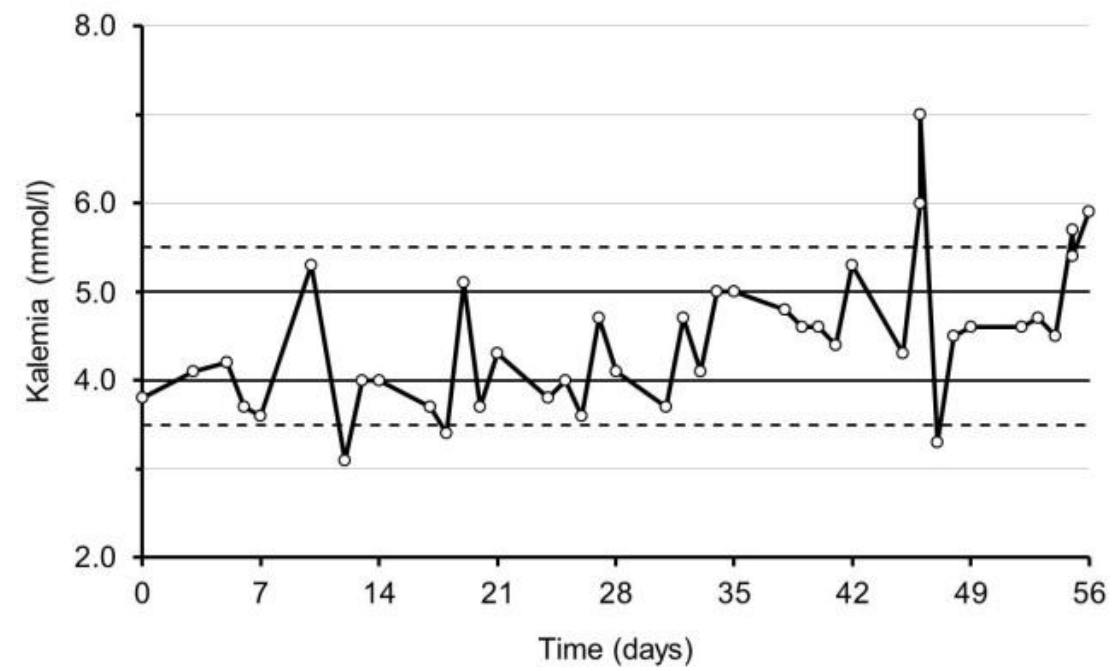

